\title{
Indagações a partir do livro L'architettura della Città, de Aldo Rossi
}

Investigations from the book L'architettura della Città, by Aldo Rossi

\section{ADALBERTO DA SILVA RETTO JÚNIOR}

Professor de projeto urbano e história do urbanismo na FAAC - Unesp Campus de Bauru, pósdoutorado como bolsista Fapesp, no Doutorado de Excelência SSAV/ Istituto Universitário di Architettura di Venezia, Doutor FAU USP/IUAV.

rettojr@faac.unesp.br/rettojr@iuav.it

\section{Resumo}

L'architettura della Città, de Aldo Rossi, abre um debate fundamental da história da cidade e da arquitetura: a cidade, na sua totalidade, aparece como um organismo vivo que se compõe de arquitetura em um binômio inseparável. Com isso, Aldo Rossi põe as bases para uma refundação objetiva e científica da disciplina, colocando a arquitetura como um fato permanente, universal e necessário que deve conhecer e reconquistar o território indiscutível da própria especulação teórica e da própria prática operativa: a cidade. Esta relação constituiu-se em uma questão teórica, cuja importância reaparece atualmente (por uma implícita aspiração a uma "unidade aquitetura-urbanismo") diante de um cenário, no qual a possibilidade de uma teoria do projeto parece completamente absorvida da extrema complexidade das formas da paisagem contemporânea.

Palavras-chave: Arquitetura e cidade, Aldo Rossi.

\section{Abstract}

L'architettura della Città, by Aldo Rossi, opens up a fundamental debate about the history of city and architecture: the city, in all its totality, looks like a living organism that is arranged with architecture in an inseparable binomial. By that, Aldo Rossi puts the bases for an objective and scientific re-foundation of the discipline and states the architecture as a permanent fact, universal and necessary, which needs to know and reconquer the unquestionable territory of its own theoretical speculation and of its own operative practice: the city. This theoretical question nowadays emerges again (because of an implicit aspiration for an architecture-urbanism unity) before a scenario, where the possibility of a project theory seems to be completely absorbed by the extreme complexity of contemporary landscape's forms. 


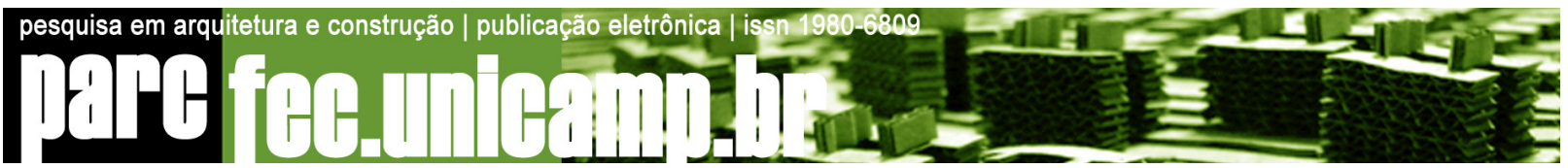

Keywords: Architecture and city, Aldo Rossi.

\section{Introdução}

L'Architettura della Città é publicado em 1966, mesmo ano de Complexity and Contradiction in Architecture de Robert Venturi, nos Estados Unidos e de II Territorio dell'Architettura, de Vittorio Gregotti, na Itália.

Sem querer se debruçar na relação, e nem mesmo, sobre as diferenças e complementariedades destes três textos, ilumina-se a partir de uma cronologia horizontal a amplitude do debate de uma geração inteira de arquitetos sobre a necessidade de redefinir coordenadas teóricas, que poderiam guiar e orientar a dimensão do fazer e do agir arquitetônico. A leitura dos três livros demonstra uma verdadeira revisão crítica da disciplina, a partir do empobrecimento do Movimento Moderno que, na forma globalizada do International Style, do segundo pós-guerra, manifesta a sua insuficiência em delinear com clareza qual deveria ser o futuro da arquitetura.

L'architettura della Città abre um debate fundamental da história da cidade e da arquitetura já explicitado no próprio título: a cidade, na sua totalidade, aparece como um organismo vivo que se compõe de arquitetura em um binômio inseparável. Com isso, Aldo Rossi põe as bases para uma refundação objetiva e científica da disciplina, cuja racionalidade não é mais autoreferencial, mas interna, de coordenadas históricas. A arquitetura, assim, é vista como um fato permanente, universal e necessário que deve conhecer e reconquistar o território indiscutível da própria especulação teórica e da própria prática operativa: a cidade.

O objetivo primário de Rossi é justamente o de definir a estrutura intrínseca na cidade, pois somente partindo de seu conhecimento e da análise da dimensão urbana, a arquitetura poderia restabelecer sua contribuição operativa. A cidade, que vem analisada e investigada pelo autor através de métodos interpretativos específicos da geografia urbana e princípios do estruturalismo, compõe-se "per parti" autônomas e reconhecíveis a partir das quais derivam as declinações específicas: o tecido repetitivo das residências e a individualidade dos monumentos.

Vale, entretanto, salientar que a produção bibliográfica rossiana não acaba com este livro, e que, para uma compreensão maior de sua reflexão, é necessário estabelecer não somente uma leitura acurada dos projetos (como documentos primários), mas também com 
outros textos do mesmo autor. De fato, o livro aqui apresentado é um texto que recolhe e sistematiza uma série de estudos, de análises e de considerações maturadas e aprofundadas no período de sua formação, no âmbito de sua escola em Milão, assim como artigos publicados na revista Casabella Continuità, dirigida naquele momento por Ernesto Nathan Rogers, onde Rossi é redator há mais de dez anos.

Apesar deste aspecto, é importante ressaltar que neste livro Aldo Rossi, empenhado na construção lógica de uma teoria a priori, não propunha um modelo paradigmático de cidade. A cidade análoga, que é apresentado somente alguns anos depois, faz parte de uma reflexão que persegue o autor por toda sua vida acadêmica e profissional.

Um outro confronto, que torna-se obrigatório quando faz-se um diálogo vertical com a obra do autor, é o seu Autobiografia Scientifica . Os dois textos, que estão separados do ponto de vista cronológico por vinte anos, foi publicado pela primeira vez nos Estados Unidos por uma solicitação de Philip Johnson. Somente chega no cenário italiano em 1991, ano em que Aldo Rossi é o primeiro italiano a receber o Pritzker Prize.

Aos estudos teóricos sobre a cidade conduzidos nos anos de 1960 e 1970, baseados sobre as lógicas abstratas do plano, Aldo Rossi contrapõe uma investigação pessoal baseada no estudo da cidade como um organismo composto de tantas partes acabadas, determinadas no curso do tempo, através de processos de transformações e de permanências, que adquirem valores específicos na memória individual e coletiva, e que constituem a essência, a alma da cidade.

A observação dos elementos que compõem a cidade transforma-se, na atividade projetual de Aldo Rossi, em memória dos próprios elementos. Estes elementos, modificados através de sucessivas depurações lingüísticas, em formas primárias, em arquétipos (como 0 cone, o cubo, a pirâmide), recompõem-se em cada arquitetura, "evocando um sentimento de vida" (Aldo Rossi - a cura di G.Braghieri - Zanichelli, Bologna, p. 11) ou exprimindo "uma nostalgia" (M.Tafuri e F. Dal Co, Architettura contemporanea, Electa, Venezia, p. 382).

A lição de "A arquitetura da cidade", traduzido para língua portuguesa em 1977 (Portugal) e em 1995 (Brasil), é também e, sobretudo, fazer perceber as relações entre história da cultura e das instituições ("A cidade grega” de Marcel Poëte; Fustel de Coulanges, etc.) e a arquitetura.

Mas, a tomada de consciência de que a cidade que se lê é aquela em que se opera, de certa forma, explica o êxito nacional e internacional da obra considerado por teóricos como um livro-tratado. Ao retornar à natureza do próprio conhecimento diante das 
transformações da arquitetura da cidade, em uma condição análoga àquela do angelus novus, de Walter Benjamin, o autor explicita a consciência do arquiteto na dupla angulação: da continuidade da própria disciplina na proposição analítica e projetual, e a fratura ocorrida socialmente, nos modos e nas expectativas de vida, sem se esbarrar em uma proposição meramente utópica. Esta relação dolorosa constituiu-se em uma questão teórica, cuja importância reaparece atualmente (por uma implícita aspiração a uma "unidade aquiteturaurbanismo") diante de um cenário, no qual a possibilidade de uma teoria do projeto parece completamente absorvida da extrema complexidade das formas da paisagem contemporânea.

\section{Os elementos primários e área-residência: a cidade "per parti"}

No livro de Rossi, o assentamento físico da cidade é decomposto em dois sistemas distintos, definidos como os "elementos primários" e "área-residência". Na individualização de tais elementos primários entram múltiplos aspectos, o caráter público e coletivo ("o aspecto coletivo parece constituir a origem e o fim da cidade" - escreve Rossi), o caráter histórico-monumental ("um edifício histórico pode ser entendido como um fato urbano primário; isso resulta desligado da sua função originária, ou apresenta no tempo mais funções, no sentido do uso a que foi destinado, enquanto não modifica a sua qualidade de fato urbano gerador de uma forma da cidade. Os monumentos são sempre elementos primários").

Os elementos primários, assim, têm uma natureza múltipla, que em síntese pode ser definida, nas palavras do autor como "aqueles elementos capazes de acelerar o processo de urbanização de uma cidade e, referindo-se a um território mais amplo, dos elementos caracterizantes os processos de transformação espacial do território. Eles agem quase sempre como catalizadores" (Rossi, 1966).

Tais elementos, no final, não são uma necessidade dos fatos físicos constítuidos: podem ser simplesmente "lugares" dotados de um valor simbólico próprio: "o fato urbano, de fato, apresenta uma qualidade específica sua, que é dada principalmente pela sua persistência em um lugar, da capacidade de desenvolver uma ação precisa, da sua individualidade". Mas não só: eles podem ser reencontrados também no "plano" da cidade : "afirmo agora - acrescenta Rossi - que considero o plano um elemento primário, da mesma forma que um templo ou um forte".

Em conclusão, ao caracterizar o conceito de elemento primário entram em jogo o caráter de constância ou de permanência do seu papel e de sua existência física no 
envolvimento com a cidade, o caráter de individualdade ou de singularidade que eles possuem, logo o caráter de elemento gerador e formativo da estrutura urbana de um determinado período histórico.

Ezio Bonfanti no texto "Elementi e Costruzione. Note sull'Architettura di Aldo Rossi", de 1970, em uma análise atenta entre os elementos e seu procedimento projetual compositivo, afirma que aquilo que caracteriza o processo de construção da obra rossiana (dos seus projetos e de seus desenhos) é uma composição por elementos acabados e autônomos, que são colocados lado a lado e reunidos, sem nenhuma possibilidade de subordinação hierárquica .

Bonfanti classifica estes elementos em duas categorias: pedaços e as partes. Os pedaços, são "elementos primários irredutíveis ulteriormente", como por exemplo as paredes muitos finas do edifício na Gallaratese ou a trave com secção triangular da ponte para a Triennale di Milano. As partes, ao contrário, "são elementos mais complexos que [...] podem coincidir com obras arquitetônicas inteiras", como o monumento-fonte de Segrate ou o volume cúbico do Monumento à Resistenza di Cuneo. Ao tomar em análise a Prefeitura e Scandicci ou a escola elementar de Fagnano Olona, Bonfanti evidencia a emergência de traços do pavillionsystem citado por Emil Kaufmann no seu livro de 1933 “De Ledoux à Le Corbusier" . De fato, a arquitetura do lluminismo, que assumiu um papel decisivo na formação de Aldo Rossi, colocou as bases para os princípios daquilo que Kaufmann define como arquitetura autônoma, nascida da destruição da Unidade Clássico-Barroca.

Sem entrar no mérito das considerações de kaufmann, o aspecto interessante e significativo levantado por Bonfanti é o caráter duplo que o conceito de parataxe assume como chave de interpretação para a obra e o pensamento do autor.

\section{A Città analoga}

Através dos estudos sobre "fatos urbanos", Aldo Rossi desenvolve uma hipótese de "progettazione della città" fundada em um processo analógico passível de ser instituído entre a estrutura urbana histórica e a construção da cidade nova: "acredito - escreve - que o modo mais sério para operar na cidade, ou para entendê-la, que não é muito diferente, seja aquele de colocar uma mediação entre a cidade real e a cidade análoga. Que esta última, em síntese, seja a autêntica projetação da cidade (...). A alternativa real é aquela de proceder à construção da cidade por analogia: em outros termos, de servir-se de uma série de elementos diferentes, entre eles ligados ao 
contexto urbano e territorial, como pilares da nova cidade" (Rossi, 1975). E interroga "Como existe uma relação autêntica, circunstanciada, com a cidade em que construímos? Isso existe - reforça Rossi, na medida em que a arquitetura remonta, nos motivos da sua própria projetação, as características gerais da cidade".

Dez anos depois do L'Architettura della Città, um livro que não propõe um modelo urbano, Aldo Rossi começa a dar forma a sua idéia de cidade, seguindo princípios presentes no livro, de que a manufatura urbana é constituída por partes autônomas e acabadas, e imaginando uma cidade em que, como nos quadros de Canaletto, somam-se e se sobrepõem às partes compondo, no final, um projeto unitário.

A teorização da Città Analoga foi elaborada a partir de 1964, na introdução do catálogo da exposição Illuminismo e architettura del '700 Veneto (Vittorio Savi, 1976 ). Todavia, é por ocasião da Biennale di Venezia de 1976, que o autor apresenta uma prancha que constitui a metáfora gráfica dos estudos e investigações sobre esta idéia.

Na prancha, apresentada como uma "obra coletiva", apresenta a casa em Borgo Ticino, a perspectiva do Gallaratese, o traçado de Monza, a Cabine dell'Elba e outras imagens do seu repertório sobrepostas ao tecido da cidade histórica e aos seus monumentos, reproduzindo uma paisagem urbana que encontra na técnica aditiva da montagem sua construção lógica.

Neste ponto, a Città Analoga se insere imediatamente em dois filões analíticos possíveis muito difundidos pelos estudiosos de Rossi: aquele dos modelos urbanos, que sempre caracterizaram o pensar da arquitetura e da cidade e, do ponto de vista da técnica, o da montagem/ collage procedimentos aditivos que filiam-se, em certa medida, à politics of "bricolage", base da reflexão do livro Collage City de Colin Rowe e Fred Koetter (1975).

Apesar de modalidades operacionais diferentes e processos não necessariamente convergentes, os resultados quando confrontados apresentam certas imagens relevantes:

1. O ponto de partida de Rossi tem base claramente estruturalista, na qual interpreta a cidade como uma estrutura física a partir da área-residência e os elementos primários. A cidade, assim, é concebida como uma manufatura, como uma obra de arte em que a cidade antiga e a cidade moderna confundem-se e se sobrepõem fazendo parte de um estudo analógico, científico e arqueológico que a partir do simbólico estabelece a ligação necessária entre o real e o imaginário.

2. Rowe e Koetter em Collage City, ao contrário, sobrepõem à realidade urbana uma análise gestáltica que, através da definição das relações entre figura-fundo, permite 
individualizar e se confrontar utilizando dois modelos urbanos como referência: a cidade antiga que produz espaços, e a cidade moderna que produz objetos. Diante dos dois modelos, que a história restitui como herança física e operativa, não existe a necessidade de uma escolha, mas simplesmente aceita-se as complexidades e as contradições do real. A cidade, dessa forma, apresenta-se como um repertório, um depósito múltiplo e complexo de formas, objetos, espaços e texturas, e a partir daí somente a prática projetual - da collage e do assemblaggio-, permite a definição da estratégia, que Colin Rowe já visualiza na Roma Imperial e Barroca ou nas construções das cidades-museus napoleônicas.

Com isto, notamos uma grande diferença entre a collage de Rowe e Koetter e a operação rossiana: para os primeiros, A Collage City não é uma reflexão sobre forma urbana, é muito mais uma estratégia. Logo, não é uma operação compositiva que culmina no projeto, o processo já é ao mesmo tempo projeto.

Não é por mero efeito de retórica que no Collage City Colin Rowe retoma e comenta criticamente definições de Claude Lévi-Strauss do "O pensamento Selvagem" :

"..o cientista", cita Rowe "cria eventos .... a partir das estruturas e o bricoleur constrói as estruturas a partir dos eventos" (Colin Rowe, Fred Koetter, pp. 168).

Colin Rowe utiliza livremente as formas e os eventos, que serão montadas e arranjadas em uma construção nova. Enquanto para Rossi, o importante é a escolha dos elementos que entram para fazer parte da composição que irá recompor e reconstruir os fragmentos da realidade.

\section{O procedimento projetual analógico}

A relação análise urbana/projeto em Aldo Rossi, vem explicitamente formulada através de uma "hipótese de uma teoria de projetação urbana - arquitetônica, onde os elementos são prefixados, formalmente definidos, mas onde o significado durante a operação tem o sentido autêntico, imprevisto, original, da investigação", já que "cada um pode reencontrar elementos fixos e racionais na própria história, e acentuar o caráter peculiar de um lugar, de uma paisagem, de um monumento" (Rossi, 1975).

A intervenção de Rossi sobre a cidade põe-se, assim, primariamente com um problema de conhecimento do significado de uma civilização urbana e da sua imagem, para posteriormente transferí-lo "analogicamente" ao projeto. Isto significa que não existe uma instrumentalização específica da projetação urbana contraposta àquela da projetação 
arquitetônica, mas que em um movimento de ir e vir os elementos do projeto arquitetônico se orientam - na experiência da projetação urbana -, com a finalidade de relacionar o objetocidade, a manufatura-cidade, a arquitetura da cidade.

A projetação urbana vem a agir sobre dois planos distintos, mas correlacionados: de um lado, em direção da projetação/ reprojetação dos nós constitutivos da estrutura urbana (histórica); do outro lado, em direção a reprojetação dos mecanismos constituintes da forma de parte isolada da cidade.

O procedimento projetual, de que Aldo Rossi é um intérprete de grande sensibilidade, também corresponde à figura retórica da metáfora na translação de significado de um objeto a outro por "íntimas, mas variadíssimas semelhanças". O novo (a invenção) torna-se, em tal caso, metáfora do antigo, retomado - por analogia - por formas estruturais, "formas tipológicas", mais ou menos ancestrais, conectadas com a cidade preexistente. Em seus projetos não são propostas formas acabadas, mas "íntimas semelhanças" derivadas das "formas estruturais": geometrias do lugar, "geometrias da memória".

Todavia - por considerações não somente dimensionais, mas também concretamente de gestão - foi eclipsada qualquer ilusão utópica da "cidade toda como arquitetura", ou melhor, de um "controle da forma urbana operado globalmente com os instrumentos da arquitetura".

A "città analoga" de Aldo Rossi introduz "um procedimento compositivo, que é permeado de alguns fatos fundamentais da realidade urbana, entorno a qual constitui outros fatos fazendo parte de um sistema analógico" (Rossi, 1975).

Para ilustrar este conceito, Rossi refere-se ao famoso capriccio palladiano de Canaletto: "os três monumentos paladianos constituem uma Veneza análoga cuja formação é completada com elementos corretos, ligados à história da arquitetura como da cidade (...). Tal operação lógico-formal pode traduzir-se em um modo de projetação" (Rossi, 1975).

O novo, no procedimento rossiano, é, sem dúvida novo, mas faz alusão ao já conhecido através de sutis retomadas, que instaura uma continuidade com o preexistente, filtrada pela memória, com uma interpretação estritamente subjetiva, mas profunda, de cores, traços somáticos, de matrizes tipológicas, de um ambiente urbano. Não tem necessariamente, neste tipo de intervenções, a busca de uma continuidade morfológica com aquilo que preexiste: a relação com as preexistências - como já dizia Rogers - é uma relação de tipo figurativo, de uma sintonia camuflada com os significados formais de um lugar e suas imagens: é uma relação de certo modo literária, poética, assimilável à interpretação (também literária e poética), que qualquer escritor elabora sobre as peculiaridades das cidades, de 
maneira sintética. Um exemplo acabado que ilustra esta relação é a síntese feita pelos pintores mais amados e estudados por Rossi, como De Chirico, interpretando as cidades da região padana, ou Sironi, as periferias lombardas. Entretanto, apesar do estudo da cidade ser a base do projeto, durante a fase projetual essa história é esquecida, uma vez que os dados simbólicos, lingüísticos, figurativos da tradição arquitetônica de uma determinada civilização histórico-geográfica, torna material operado na impostação do projeto.

O procedimento de Rossi está presente e encontra respaldo na definição, de 1978, do recém-fundado Dipartimento di Teoria e Tecnica della Progettazione Urbana do Istituto Universitario di Architettura di Venezia (I.U.A.V.), que assumia como campo de estudo "a projetação urbana - arquitetônica em relação a um contexto dado, interpretado nos seus componentes de história, de morfologia, de funções".

De fato, Rossi somente assume uma cadeira como professor efetivo na Universidade de Veneza, em 1975, depois de ter sido professor asistente de Ludovico Quaroni, em 1963, na escola de Urbanismo de Arezzo, e de Carlo Aymonino, no Istituto Universitario di Architettura di Venezia. A partir de 1965 ensina na Università de Milão, Zurique e em diversas Universidades dos Estados Unidos.

Nas palavras de Gianugo Polesello, então diretor do departamento: "Afirmei que a Arquitetura e o Plano já se contituem em domínios científicos separados, tecnicamente definidos. Não pretendo aqui postular uma reconquista da unidade entre Arquitetura e Plano (...). Afirmo, porém, que o problema do town-design como disciplina ou como ciência autônoma e separada, é restrito de significado, seja a respeito aos resultados arquitetônicos, seja daqueles urbanísticos, do plano. O problema não é aquele da coincidência entre Arquitetura e Plano, que são mantidos autonômos e independentes do ponto de vista técnico e teórico-científico, mas sim o da Projetação da Cidade" (Grandinetti e Pittaluga, 1992). A "projetação urbana" "vem assim se qualificar, não tanto como 'disciplina' em si mesma e 'técnica' específica, quanto como tema, que tem por objeto a cidade e a sua definição física e formal. A cidade é, assim, o objeto e o fim último da projetação urbana. Ela pode usar, instrumentos do Plano (como estratégia de reordenação e localização, funcional, econômico...) e da Arquitetura (como técnica de intervenção direta na construção da cidade)".

Revisitar as biografias científicas de personagens, trajetórias profissionais como Rossi, assim como de outros arquitetos do cenário italiano como Vittorio Gregotti, Gianugo Polesello, Giorgio Grassi, Carlo Aymonino, Giancarlo de Carlo, Bernardo Secchi e Gino Valle, permite explicitar de forma cabal uma relação entre teoria do projeto e visão racionalizada da cidade e do território - que significa, antes de tudo, considerar a possibilidade de uma 


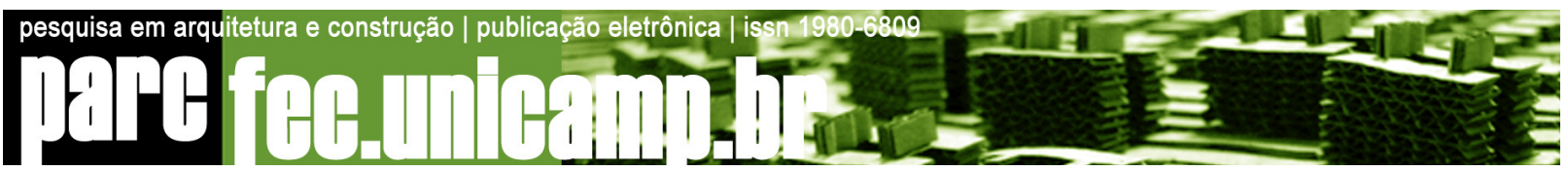

dimensão discursiva e operativa no fazer, sem criar simples (ou simplistas) procedimentos de causa e efeito.

\section{Referências}

AA. VV., Teoria della progettazione architettonica, Bari, Edizioni Dedalo, 1985.

BONFANTI, Ezio, Elementi e Costruzione. Note sull'architettura di Aldo Rossi, in Ezio Bonfanti, Scritti di Architettura, a cura di Luca Scacchetti, Milano, Clup, 1981, pp. 281- 296.

FERLENGA, Alberto, a cura di, Aldo Rossi. Architetture 1959-1987, Milano, Electa, 1990.

MONEO, Rafael, L'idea di architettura in Rossi e il Cimitero di Modena, in Moneo Rafael, La solitudine degli edifici e altri scritti. Sugli architetti e il loro lavoro, a cura di Andrea Casiraghi e Daniele Vitale, Torino, Umberto Allemandi \& C., 2004, pp. 11-59.

MONEO, Rafael, L'apparenza come realtà. Considerazioni sull'opera di Aldo Rossi, in Moneo Rafael, La solitudine degli edifici e altri scritti. Sugli architetti e il loro lavoro, a cura di Andrea Casiraghi e Daniele Vitale, Torino, Umberto Allemandi \& C., 2004, pp. 61-71.

MONEO, Rafael, Inquietudine teorica e strategia progettuale nell'opera di otto architetti contemporanei, Milano, Electa, 2005, pp. 91-121.

MOSCHINI, Francesco, a cura di, Aldo Rossi. Progetti e Disegni 1962-1979, Firenze, centro Di, 1979.

POSOCCO, Pisana, RADICCHIO, Gemma, RAKOWITZ, Gundula, a cura di, Care Architetture. Scritti su Aldo Rossi, Torino, Umberto Allemandi \& C., 2002.

ROSSI, Aldo, L'Architettura della Città, Torino, CittàStudiEdizioni, 1995.

ROSSI, Aldo, Autobiografia Scientifica, Parma, Pratiche Editrice, 1999.

ROSSI, Aldo, Scritti scelti sull'architettura e la città, a cura di Rosaldo Bonicalzi, Milano,Clup, 1975.

ROSSI, Aldo, Architettura per i musei, in AA. VV., Teoria della progettazione architettonica, Bari, Edizioni Dedalo, 1985, pp. 123-137.

ROSSI,i Aldo, Lettera ad Ezio Bonfanti, 3 gennaio 1971, in Bonfanti Ezio, Nuovo e Moderno in Architettura, a cura di Marco Biraghi e Michelangelo Sabatino, Milano, Bruno Mondatori, 2001, pp. 367369.

ROWE, Colin, Koetter Fred, Collage City, Milano, II Saggiatore, 1981

SAVI, Vittorio, L'architettura di Aldo Rossi, Milano Franco Angeli Editore, 1976.

TAFURI, Manfredo, II caso Aldo Rossi, in Tafuri Manfredo, Storia dell'Architettura Italiana.1944-1985, Torino, Einaudi, 2002, pp. 166-171.

DAL CO, Francesco, Ora questo è perduto. II Teatro del Mondo di Rossi alla Biennale di Venezia, in Lotus International, $\mathrm{n}^{\circ} 25,1980$, pp. 66-70.

LAMPUGNANI, Vittorio, Utopia assente. Frammenti per una storia critica, in Casabella, $\mathrm{n}^{\circ}$ 487-488, 1983. 


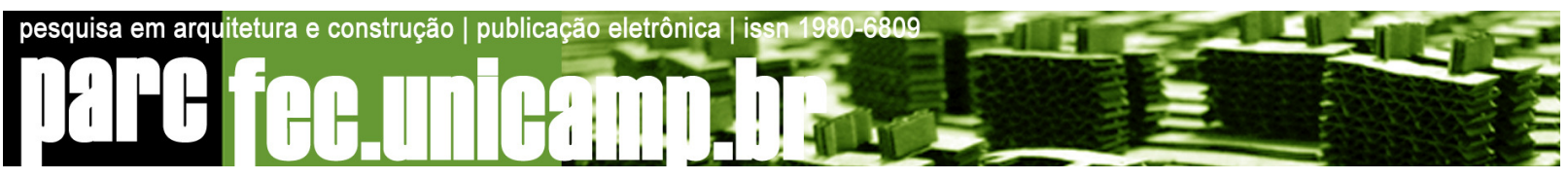

ROSSI, Aldo, La città analoga:tavola, in Lotus n¹3, Dicembre 1976, pp. 5-9.

TAFURI, Manfredo, Ceci n'est pas une ville, in Lotus $n^{\circ} 13$, Dicembre 1976, pp. 10-13.

VITALE, Daniele, Ritrovamenti, traslazioni, analogie. Progetti e frammenti di Aldo Rossi, in Lotus International, $\mathrm{n}^{\circ} 25,1980$, pp. 55-59. 